\title{
Effect of ground motion filtering on the dynamic response of a seismically isolated bridge with and without fault crossing considerations
}

\author{
Shuo Yang ${ }^{a}$, George P. Mavroeidis ${ }^{\mathrm{a}, *}$, Alper Ucak ${ }^{\mathrm{b}}$, Panos Tsopelas ${ }^{\mathrm{c}}$ \\ ${ }^{a}$ Department of Civil and Environmental Engineering and Earth Sciences, University of Notre Dame, Notre Dame, IN 46556, USA \\ ${ }^{b}$ McMillen Jacobs Associates, 5301 Shawnee Rd \#400, Alexandria, VA 22312, USA \\ ${ }^{c}$ Department of Mechanics, School of Applied Mathematical and Physical Sciences, National Technical University of Athens, Zografou \\ 15773, Greece
}

\begin{abstract}
High-pass filtering not only removes the low-frequency noise from the near-fault ground motion records, but also eliminates the permanent ground displacement and reduces the dynamic ground displacement. This may considerably influence the calculated seismic response of a spatially extended engineering structure crossing a fault rupture zone. To demonstrate the importance of incorporating permanent ground displacements in the analysis and design of extended structures under specific fault crossing conditions, the dynamic response of a seismically isolated bridge located in the vicinity of a surface fault rupture ("Case A") or crossing a fault rupture zone ("Case B") is calculated by utilizing a near-fault ground motion record processed with and without a displacement offset. The seismically isolated bridge considered in this study is a 10-span continuous structure supported by 11 piers, resembling a typical segment of the $2.3 \mathrm{~km}$ long Bolu Viaduct 1 located in west-central Turkey. The Lucerne Valley record from the $1992 M_{\mathrm{w}} 7.2$ Landers earthquake, which preserves a permanent ground displacement in the fault-parallel direction and exhibits a large velocity pulse in the fault-normal direction, is used as the basis for investigating the effect of high-pass filtering on the dynamic response of the bridge. For the seismically isolated bridge located in the vicinity of the surface fault rupture ("Case A"), the utilization of the high-pass filtered ground motion leads to underestimating the demands of pier top, pier bottom and deck displacements. However, the demands of isolation displacement, isolation permanent displacement and pier drift are almost identical for both the unfiltered and filtered versions of the ground motion record. On the other hand, for the seismically isolated bridge traversed by a fault rupture zone (“Case B"), all response quantities are significantly underestimated when the high-pass filtered ground motion is used. These results, though limited to a single bridge structure and a single ground motion input, clearly indicate the importance of permanent ground displacement on the dynamic response of spatially extended engineering structures crossing fault rupture zones.
\end{abstract}

Keywords: bridge; seismic isolation; fault crossing; permanent ground displacement; high-pass filtering; near-fault ground motion

\footnotetext{
* Corresponding author. Tel.: +1-574-631-6245.

E-mail address: g.mavroeidis@nd.edu
} 


\section{Introduction}

Strong motion records are of fundamental importance in earthquake engineering design, but quite frequently they are contaminated by broadband noise limiting the frequency range over which useful data can be obtained. The influence of noise in strong motion records is most pronounced at high and low frequencies where the signal-to-noise ratio is typically low compared to that at the intermediate frequencies [1].

For analog accelerographs the high-frequency noise is primarily associated with the correction for instrument response, whereas for digital accelerographs the high-frequency noise is commonly related to the low resolution of the analog-to-digital converter, the effect of ambient, wind or wave sources at the location of the instrument, and the monoharmonic high-frequency noise caused by the proximity of the instrument to electrical generators or vibrating machinery [2]. The high-frequency noise is usually removed by applying a low-pass (high-cut) filter to the accelerogram, a correction that may not always be necessary depending on the intended use of the data and the particular characteristics of the highfrequency noise.

On the other hand, the low-frequency noise has been attributed to instrumental errors such as transducer misalignment and cross-axis sensitivity [3,4], mechanical or electrical hysteresis within the transducer system [5], and analog-to-digital conversion [6,7], as well as to natural distortions such as tilting and torsion of the ground in the vicinity of the instrument [8-12]. These instrumental errors and natural distortions generate small offsets in the baseline of the recorded ground accelerations, which in turn amplify upon integration resulting in significant drifts in the ground velocities and displacements, as well as in noticeable effects in the long-period range of the corresponding response spectra. The lowfrequency noise is typically removed by high-pass (low-cut) filtering with corner frequencies often chosen based on the shape of the Fourier amplitude spectra and the signal-to-noise ratio.

Though high-pass filtering is effective in reducing the low-frequency noise in accelerograms, this may not always be the most desirable approach for processing near-fault records with a large permanent ground displacement interpreted as coseismic displacement of the ground due to slip on the fault. The reason is that high-pass filtering does not allow for displacement time series to have a static offset (corresponding to zero frequency), and therefore this lack of a permanent ground displacement in nearfault records may significantly affect the calculated seismic response of spatially extended engineering structures under specific fault crossing conditions. However, retrieving the true permanent ground displacement directly from an accelerogram is still an open problem in strong motion seismology as discussed in Section 2.

The main objective of this study is to demonstrate the importance of incorporating permanent ground displacements in the analysis and design of spatially extended engineering structures under 
specific fault crossing conditions. To achieve this objective, the dynamic response of a seismically isolated bridge located in the vicinity of a surface fault rupture ("Case A") or crossing a fault rupture zone ("Case B") is calculated by utilizing a near-fault ground motion record processed with and without a displacement offset.

\section{Permanent Ground Displacement}

Permanent ground displacement (also known as static displacement, residual displacement, displacement offset, permanent translation or fling step) is the flat level near the end of the baselinecorrected displacement time series derived from accelerograms at stations in the vicinity of a fault. The permanent ground displacement is interpreted as the coseismic deformation of the ground due to dislocation across the fault surfaces. The permanent ground displacement typically varies between a few centimeters to several meters depending on the local slip (i.e. slip on the immediate fault segment), the depth of burial of the fault, and the fault-to-station distance. An informative discussion on the characteristics of the permanent ground displacement in the vicinity of a fault for various types of movement (strike-slip, oblique, dip-slip), faulting depth (surface vs. buried), and slip distribution (uniform vs. variable) based on numerical simulations is presented by Dreger et al. [13]. The permanent ground displacement appears in the direction of the slip vector on the fault, and therefore manifests itself in the strike-parallel direction for strike-slip faults and in the strike-normal and vertical directions for dipslip faults (e.g. [14,15]). It should also be noted that permanent translation along with forward rupture directivity are the two main causes of the pulse-like ground motions observed in the near-fault region (e.g. $[14,15])$ which have been identified as critical in the design of structures (e.g. [16-18]).

A considerable effort has been expended by seismologists and engineers over the last four decades to maximize the data return from accelerographs by retrieving the permanent ground displacement (e.g. [5,11,19-30]). These studies have proposed various processing schemes that involve, instead of high-pass filtering, baseline correction in an attempt to recover the permanent ground displacement directly from accelerograms. However, this problem has proved to be particularly challenging because the computed displacement offset may not be the true permanent ground displacement, but it may also incorporate the effects of natural distortions (such as tilting and torsion of the ground in the vicinity of the instrument) and instrumental errors (such as transducer misalignment and cross-axis sensitivity, mechanical or electrical hysteresis within the transducer system, and analog-todigital conversion). These natural distortions and instrumental errors cause small offsets in the baseline of the accelerograms resulting in drifts in the velocity and displacement time series upon integration, making it difficult to fully understand the source of the baseline offsets for any given record and eventually recover the true permanent ground displacement. Evidently, these offsets cannot be removed by applying 
a high-pass filter to the accelerogram because such a procedure would preclude extracting the permanent ground displacement from the acceleration record.

Early studies indicated that permanent ground displacements derived directly from accelerograms using empirical baseline correction schemes are in most cases sensitive to the choice of the parameters for the baseline correction, and variations of these parameters may yield seemingly plausible displacement waveforms with very different offsets (e.g. [11,22]). To reduce this uncertainty, subsequent research studies focused on providing more robust guidelines for the selection of the parameters for baseline correction and then grid searching for displacement waveforms that most resemble a ramp or step function (e.g. [23,26,28]).

Independently determined geoedetic data, such as Global Positioning System (GPS) measurements (preferably at stations collocated with accelerograph stations) and Interferometric Synthetic Aperture Radar (InSAR) observations, have also been used to assess the accuracy of baseline correction schemes in estimating the true permanent ground displacement (e.g. [11,22,23,28-30]). This presumes that the entire static displacement (obtained from static GPS measurements or InSAR observations) occurs during the earthquake with no postseismic deformation taking place in the averaging period following the event. These studies have shown that permanent ground displacements obtained from baseline correction schemes do not routinely converge to the correct value of the static displacement as inferred from static GPS measurements. Even the addition of static GPS data as a constraint to the baseline correction procedure does not necessarily guarantee convergence to the correct value of the static displacement, and even if the correct static offset is obtained the dynamic component of the displacement waveform may be in error by large amounts [30].

To overcome these limitations, recent studies have utilized high-rate GPS measurements (which provide accurate displacement data in a kinematic mode) as an additional constraint in the computation of the ground displacement time series during strong shaking and after strong shaking has ceased (e.g. $[24,27,30])$. This is achieved by combining high-rate GPS and accelerometer data to produce broadband displacements (i.e. displacements capturing both transient phenomena and static deformation) using a Kalman filter or other similar methods proposed in the literature. These studies have shown promising results in producing reliable broadband displacements without any subjective judgement. However, as pointed out by Melgar et al. [30], the collocation of high-rate GPS and strong motion stations is still the exception rather than the norm.

The explanation for the difficulties in retrieving the true permanent ground displacement directly from accelerograms has been provided by Graizer [9,10,31] and Trifunac and Todorovska [12]. Permanent ground displacements can accurately be calculated provided that all six components of strong motion at a particular point (corresponding to three translational and three rotational degrees of freedom) 
have simultaneously been recorded, and the records are corrected for instrumental errors. This is particularly true in the near-fault region where the response of the ground may be nonlinear [12]. However, six-component accelerometers measuring three translations and three rotations (or alternatively three-component translational accelerometers in combination with gyroscopes) are not commercially available. Therefore, the three-component translational accelerometers used in practice are incapable of distinguishing between translational and rotational motions. As a result, rotational motions are registered as fictitious translations causing offsets in the baseline of the accelerograms and leading to unphysical drifts in velocity and displacement waveforms upon integration. As stated by Graizer [31], additional information (such as simultaneous recording of rotations) should be used to verify the recovered permanent ground displacement. If this information is not available, classic data processing methods combining integration with bandpass filtering (e.g. [32,33]) should be used to provide reliable calculation of ground displacements in a limited frequency range, evidently sacrificing the estimated permanent ground displacement which may not be reliable after all.

Therefore, the objective of retrieving the permanent ground displacement and obtaining reliable estimates of the broadband displacement time series on a routine basis from accelerometer data alone remains elusive. As stated by Graizer [10,31], this objective can be accomplished only on a record-byrecord basis and under special circumstances or favorable conditions (i.e. ground motion is purely translational or rotational components are also recorded, record satisfies signal-to-noise ratio requirement, pre- and post-event memory portions of accelerogram are of low amplitude and sufficient duration).

\section{Effect of Ground Motion Filtering on Lucerne Valley Record}

The $1992 M_{\mathrm{w}} 7.2$ Landers earthquake occurred on a system of vertical right-lateral strike-slip faults in southern California [34]. The ground shaking was recorded on an SMA-2 accelerograph installed at the Lucerne Valley (LUC) station at a distance of approximately $1.1 \mathrm{~km}$ from the surface rupture (Fig. 1). This is considered to be an important strong motion record because LUC was the only station in the immediate vicinity of the 1992 Landers earthquake and was affected both by forward rupture directivity and permanent translation effects.

Iwan and Chen [21] (see also Chen [35]) developed and validated a data processing procedure to perform instrument and baseline corrections for the LUC record in an attempt to recover useful longperiod information. The LUC record processed by Iwan and Chen [21], which preserves a permanent ground displacement in the fault-parallel direction and exhibits a large velocity pulse in the fault-normal direction, is used in the present study as the basis for investigating the effect of high-pass filtering on the dynamic response of a seismically isolated bridge located in the vicinity of a surface fault rupture ("Case A") or crossing a fault rupture zone (“Case B"). 


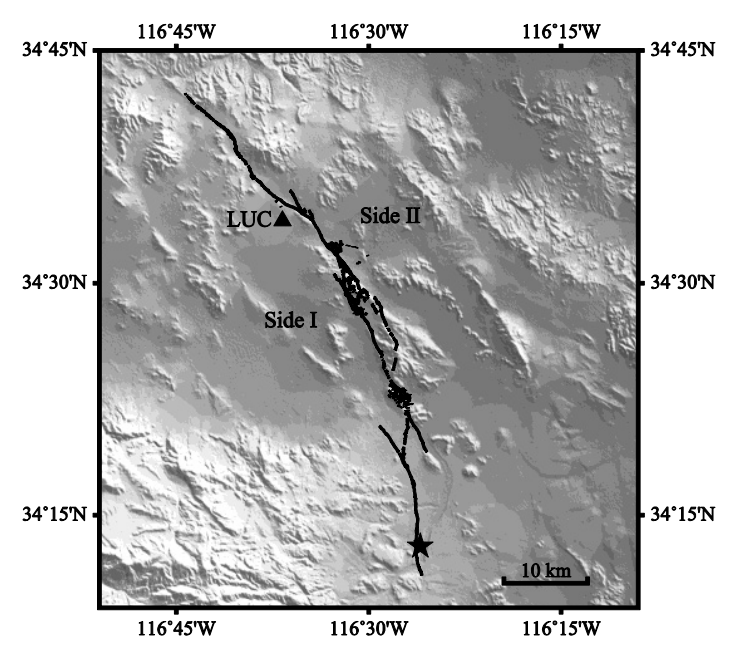

Fig. 1. Map view of the $1992 M_{\mathrm{w}} 7.2$ Landers earthquake illustrating the epicenter, the location of LUC station, and the fault trace.

Fig. 2a illustrates the unfiltered and filtered time series of ground acceleration, velocity and displacement in the fault-normal and fault-parallel directions at LUC station affected by forward rupture directivity and permanent translation, respectively. The unfiltered version is the ground motion record as processed by Iwan and Chen [21], whereas the filtered version was obtained by applying the processing scheme proposed by Ancheta et al. [36] to the unfiltered ground acceleration. This processing scheme involves various steps including application of a fourth-order high-pass acausal Butterworth filter with a corner frequency of $0.08 \mathrm{~Hz}$ to the unfiltered ground acceleration, baseline correction forcing the ground velocity and displacement time series to go to zero at the end of the record, and integration of the filtered and baseline-corrected ground acceleration to obtain compatible ground velocity and displacement time series. It should be noted that the corner frequency of $0.08 \mathrm{~Hz}$ used in this study corresponds to the $\sim 50^{\text {th }}$ percentile of the distribution of high-pass corner frequencies within the NGA-West2 ground motion database for earthquake magnitudes greater than 6.0 and distances less than $20 \mathrm{~km}$ [37].

Fig. 2a shows that high-pass filtering has (a) negligible effect on the ground acceleration time series in the fault-normal and fault-parallel directions, (b) small-to-moderate effect on the ground velocity and displacement time series in the fault-normal direction, and (c) moderate-to-large effect on the velocity and displacement time series in the fault-parallel direction. It is evident that high-pass filtering completely eliminates the permanent ground displacement and significantly reduces the dynamic ground displacement in the fault-parallel direction. The level of reduction in the dynamic ground displacement depends on the selected value of the high-pass corner frequency [37]. The equal-ductility deformation response spectra of the 5\%-damped elastic-perfectly plastic single-degree-of-freedom (SDOF) oscillator shown in Fig. 3, obtained using the SeismoSignal program [38], further demonstrate the effect of highpass filtering on spectral amplitudes in the long-period range especially for the fault-parallel component. 
a
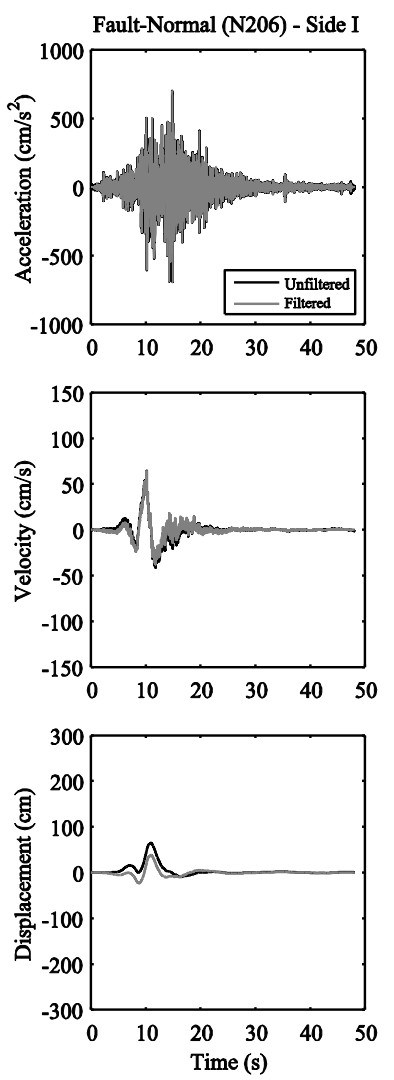

b
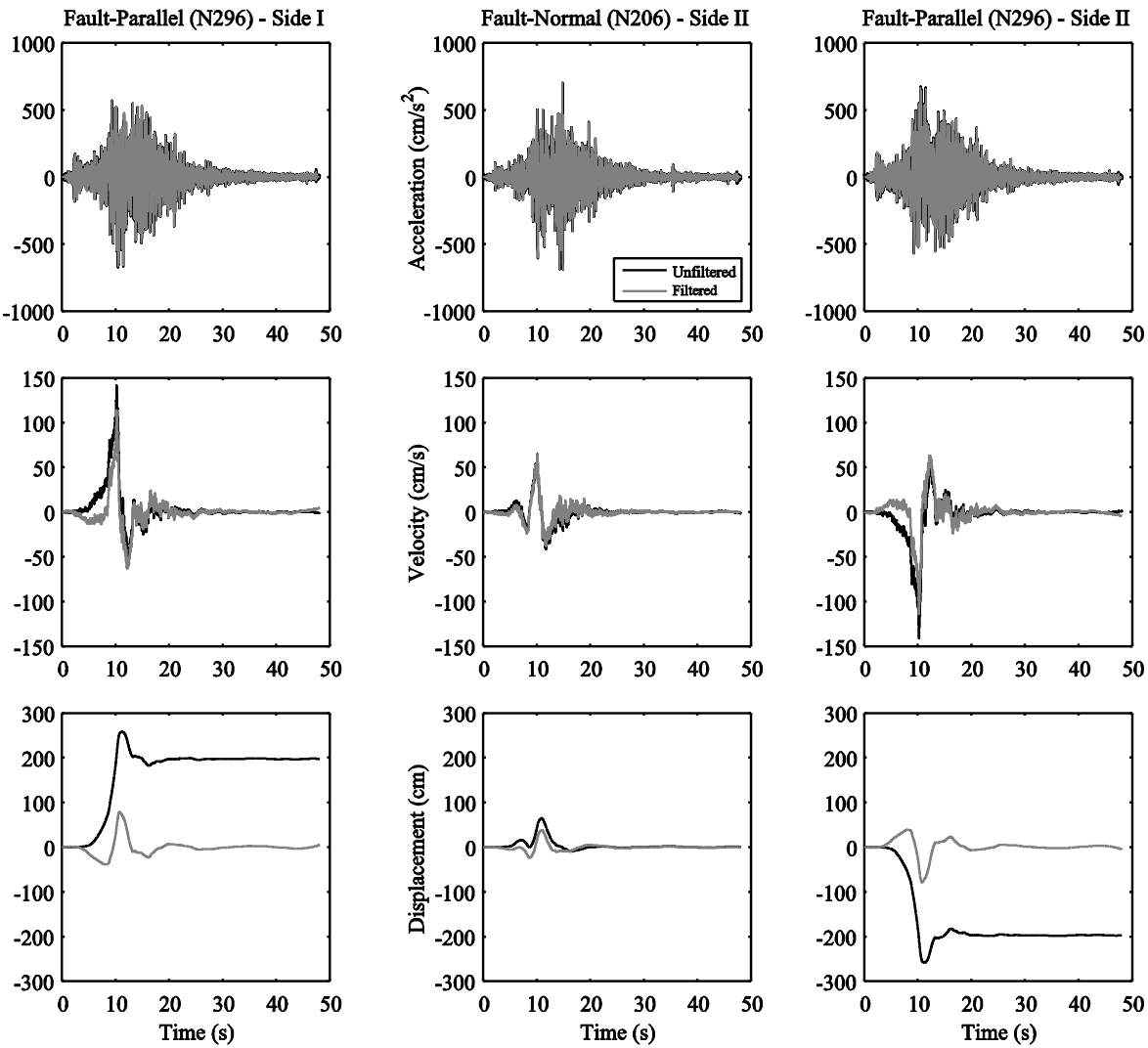

Fig. 2. Unfiltered (black) and filtered (gray) time series of ground acceleration, velocity and displacement in the fault-normal and fault-parallel directions (a) recorded at LUC station (Side I) and (b) generated on Side II in the vicinity of LUC station using a simplified approach.
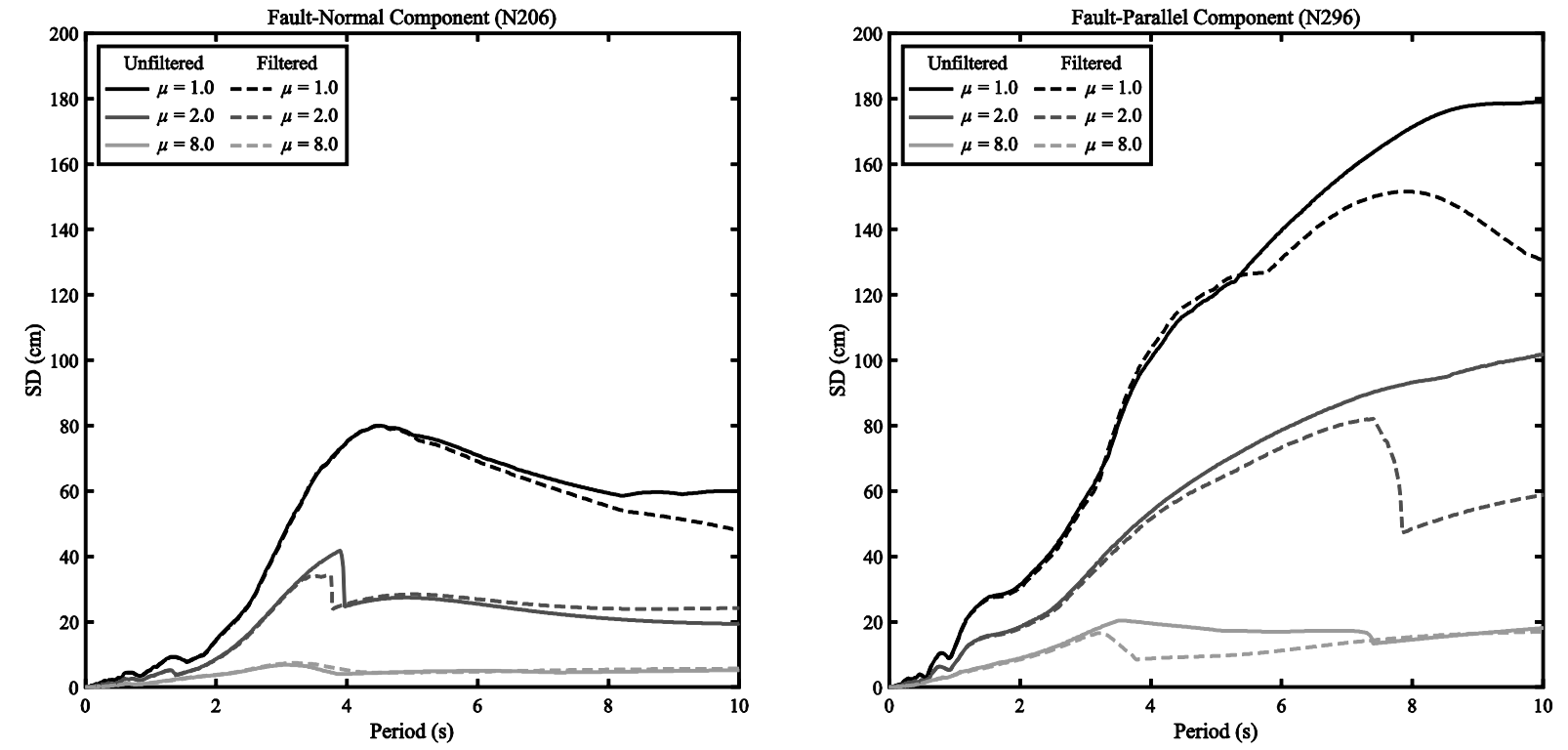

Fig. 3. Equal-ductility $(\mu=1,2,8)$ deformation response spectra of an elastic-perfectly plastic SDOF oscillator (5\% damping) subjected to the unfiltered and filtered LUC record shown in Fig. 2a. 
The ground acceleration, velocity and displacement time series shown in Fig. 2a were recorded at LUC station (Side I in Fig. 1). For investigating the effects of fault crossing on spatially extended engineering structures, it is also necessary to quantify the ground motion on the opposite side of the surface rupture (Side II in Fig. 1). Since this information is not available for the 1992 Landers earthquake, the ground motion on Side II in the vicinity of LUC station is estimated using the simplified approach described by Ucak et al. [39]. Specifically, the fault-normal component for Side II is assumed to be identical to the fault-normal component for Side I in order to ensure kinematic continuity in the faultnormal direction. To account for the ground dislocation in the fault-parallel direction across the rupture, the fault-parallel component for Side II is assumed to be equal in magnitude to the fault-parallel component for Side I but with reversed polarity. Fig. $2 b$ illustrates the horizontal ground motions on Side II generated using the aforementioned simplified approach.

It should be pointed out that this approach is based on the following assumptions: (a) the ground dislocation is distributed equally among the two sides of the fault, and (b) the LUC record (obtained at a distance of $\sim 1.1 \mathrm{~km}$ from the surface rupture) is representative of the ground shaking adjacent to the fault. The first assumption is readily satisfied because the 1992 Landers earthquake was caused by a vertical fault that experienced pure strike-slip motion. On the other hand, the second assumption involves some level of approximation, but is considered to be appropriate for the following reasons: (a) the objective of this study is not to model the response of an actual bridge traversed by the fault rupture zone of the 1992 Landers earthquake, an analysis that would require knowledge of the actual ground motion on opposite sides of the surface rupture at the particular fault crossing location, but rather to demonstrate the effect of high-pass filtering on the dynamic response of spatially extended engineering structures, and (b) no other record exists closer to a surface fault rupture characterized by documented evidence of permanent ground displacement and decoupling of forward rupture directivity and permanent translation effects.

\section{Bridge Structure and Finite Element Model}

Nonlinear time history analyses are conducted to investigate the effect of ground motion filtering on the dynamic response of a seismically isolated bridge with and without fault crossing considerations. The seismically isolated bridge considered in this study is a 10-span continuous structure supported by 11 piers $39.2 \mathrm{~m}$ apart from each other (Fig. 4a). It resembles a typical segment of the $2.3 \mathrm{~km}$ long Bolu Viaduct 1 located in west-central Turkey, which was subjected to fault crossing during the $1999 M_{\mathrm{w}} 7.2$ Duzce earthquake [39].

The geometric and mechanical properties of the bridge under consideration are identical to the ones described by Ucak et al. [39], except for the pier height which is assumed to be $30 \mathrm{~m}$ in this study. Each pier is equipped with two bilinear elastoplastic isolation bearings. The lumped isolation yield 
strength at each pier (two bearings) is equal to $0.06 W_{\mathrm{d}}$, where $W_{\mathrm{d}}$ is the tributary deck weight. The seismic isolation period, $T_{\mathrm{b}}$, defined based on the postyielding stiffness, $K_{\mathrm{b}}$, is $3.4 \mathrm{~s}$, where $T_{\mathrm{b}}=2 \cdot \pi\left(W_{\mathrm{d}} / \mathrm{g} / K_{\mathrm{b}}\right)^{1 / 2}$. The force-displacement relationship of the isolation system (two bearings) lumped at each pier is shown in Fig. 5.

a

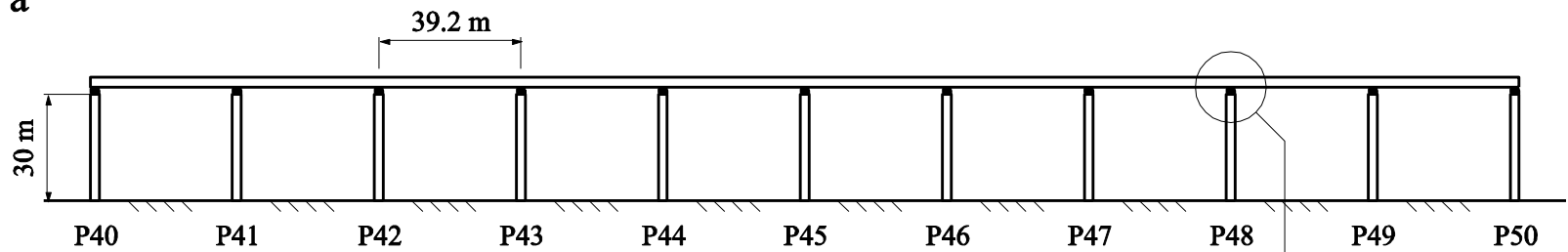

b
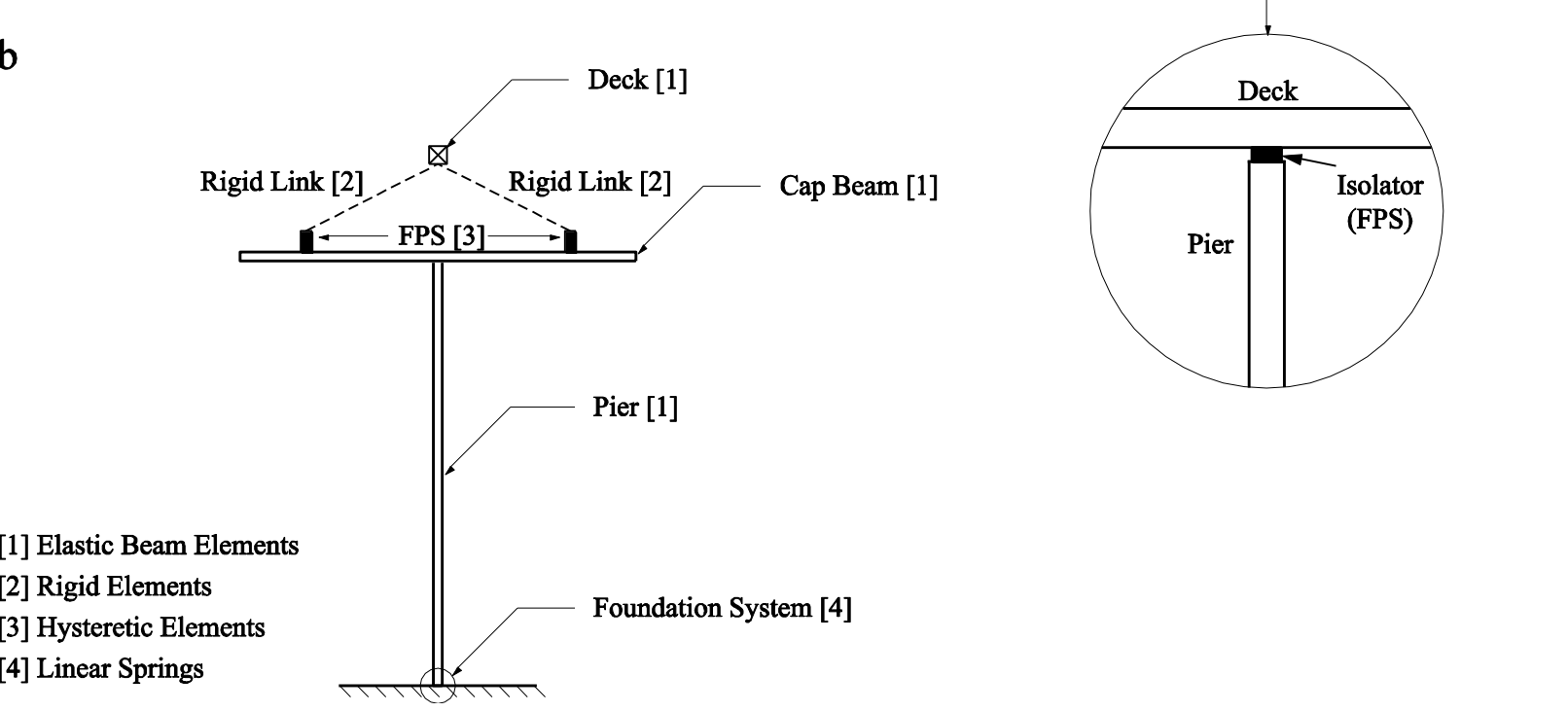

Fig. 4. Schematic presentations of (a) analyzed bridge segment and (b) finite element model for a typical pier.

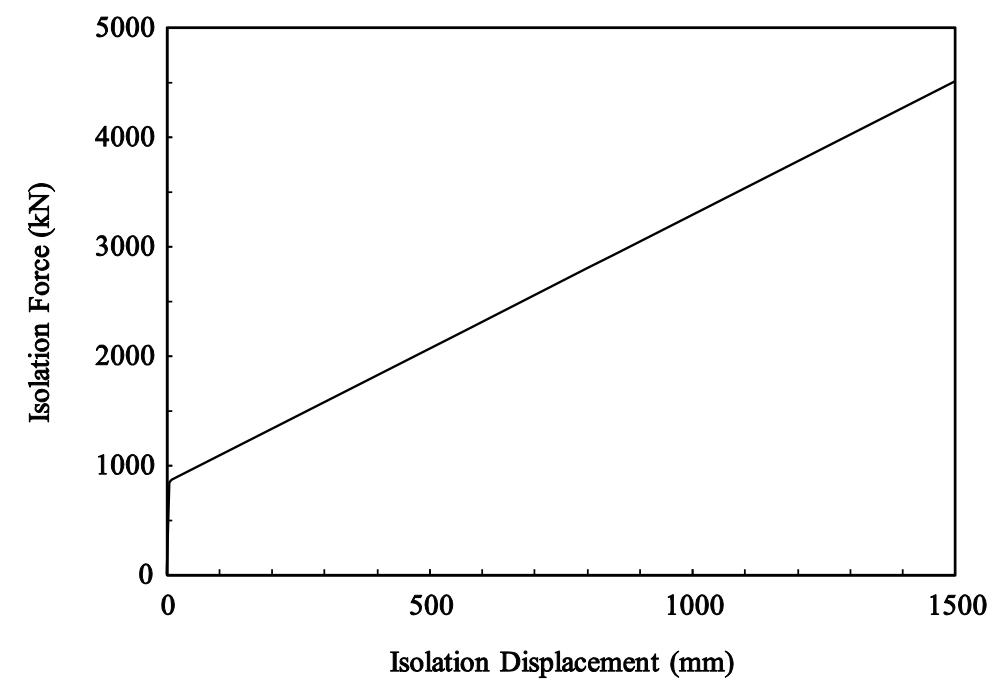

Fig. 5. Force-displacement relationship of isolation system. 
The nonlinear time history analyses are performed using the commercially available finite element software Abaqus/Standard [40]. A 3D stick model, similar to the one used by Ucak et al. [39], is employed. The pier, cap beam and deck are modeled with 3D elastic beam elements, whereas the foundation is modeled with elastic translational and rotational springs. The isolation system is modeled with 3D elastoplastic pipe elements. The centroid of the deck is connected to the isolation system with rigid links. The finite element model of a typical pier is shown in Fig. $4 \mathrm{~b}$.

Two different scenarios are considered in this study. In the first scenario ("Case A"), the bridge is assumed to be located in the vicinity of a right-lateral strike-slip fault (Fig. 6a). In the second scenario ("Case B"), the bridge is assumed to cross a right-lateral strike-slip fault between piers P44 and P45 (Fig. 6b). In both scenarios, the angle between the fault strike and the longitudinal axis of the bridge is assumed to be $30^{\circ}$. For "Case A", all piers are excited at their bases by the same longitudinal and transverse ground motions (Side II). For "Case B", piers P40 through P44 are excited by the longitudinal and transverse ground motions obtained on Side II, whereas piers P45 through P50 are excited by the longitudinal and transverse ground motions on Side I. Because the considered bridge segment is relatively short, the effect of wave passage on the spatial variability of ground motion is ignored in both scenarios. It should be noted that the longitudinal and transverse ground motions on opposite sides of the surface rupture are obtained by rotating the fault-normal and fault-parallel components of ground motion shown in Fig. 2 to the longitudinal and transverse directions of the bridge. The nonlinear time history analyses are conducted using both the unfiltered and filtered versions of the LUC record to facilitate comparison.

a

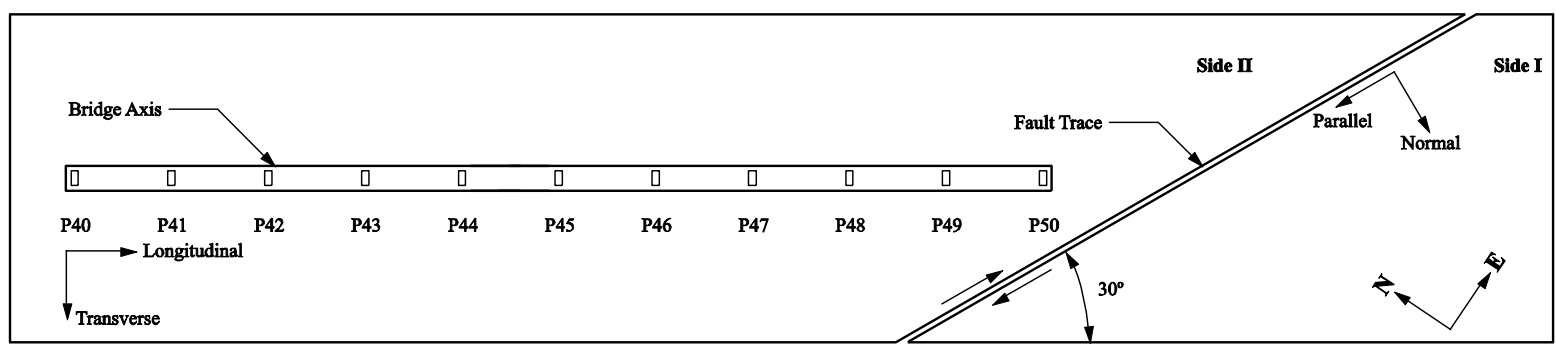

b

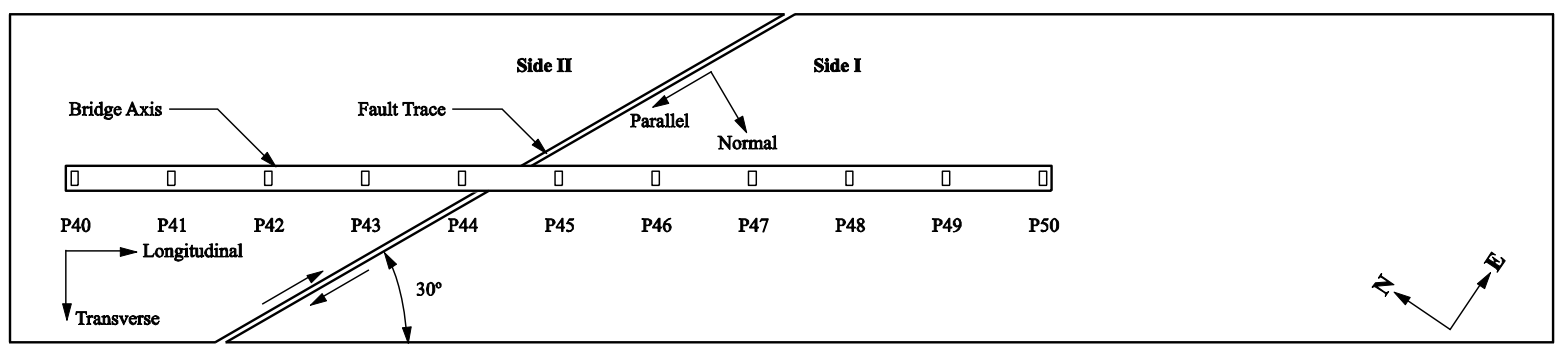

Fig. 6. Schematic presentation of the analyzed bridge segment (a) located in the immediate vicinity of the surface fault rupture ("Case A") and (b) crossing the fault rupture zone between piers P44 and P45 ("Case B"). 


\section{Analysis Results}

Fig. 7 shows the time histories of deck displacement, pier top displacement, pier base displacement, isolation displacement and pier drift in the longitudinal and transverse directions for "Case A" at pier P44 obtained using the unfiltered and filtered LUC record. The isolation displacement is defined as the relative displacement between the deck and the pier top. The force-displacement hysteresis loops of the isolation system at pier P44 are also presented in Fig. 8. Fig. 7 indicates that while high-pass filtering affects the deck, pier top and pier bottom displacement time histories, the time histories of isolation displacement and pier drift are almost identical for the unfiltered and filtered versions of the LUC record. This implies that the removal of the permanent ground displacement through filtering does not affect significantly the dynamic response of the seismically isolated bridge located in the vicinity of the surface fault rupture. A similar observation was made by Burks and Baker [41] with regard to the collapse capacity of nonlinear SDOF structures using records with permanent ground displacement preserved via baseline correction and permanent ground displacement removed via filtering.
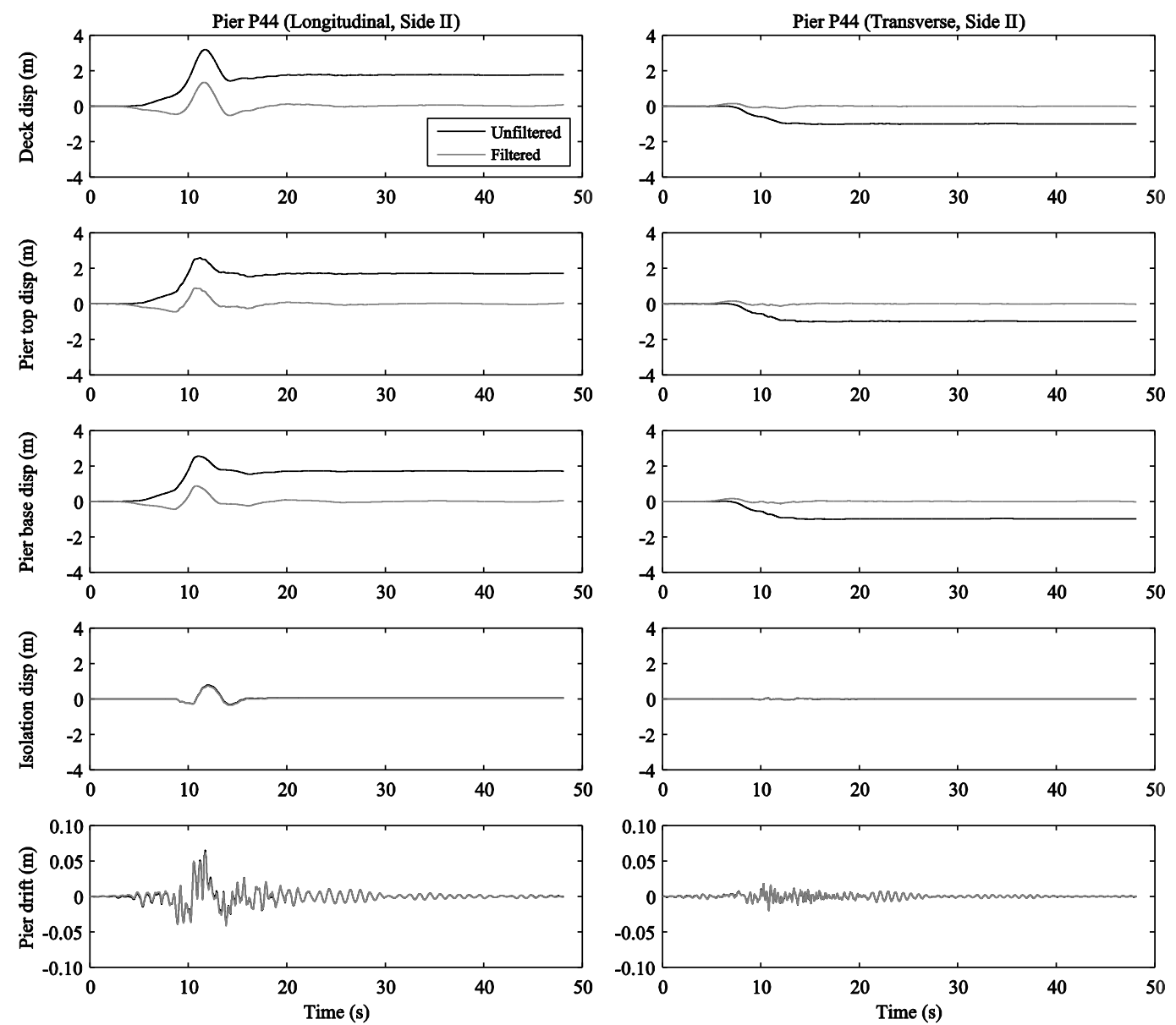

Fig. 7. Time history responses of deck displacement, pier top displacement, pier base displacement, isolation displacement, and pier drift at pier P44 for "Case A" (ignoring fault crossing) using the unfiltered and filtered LUC record. 

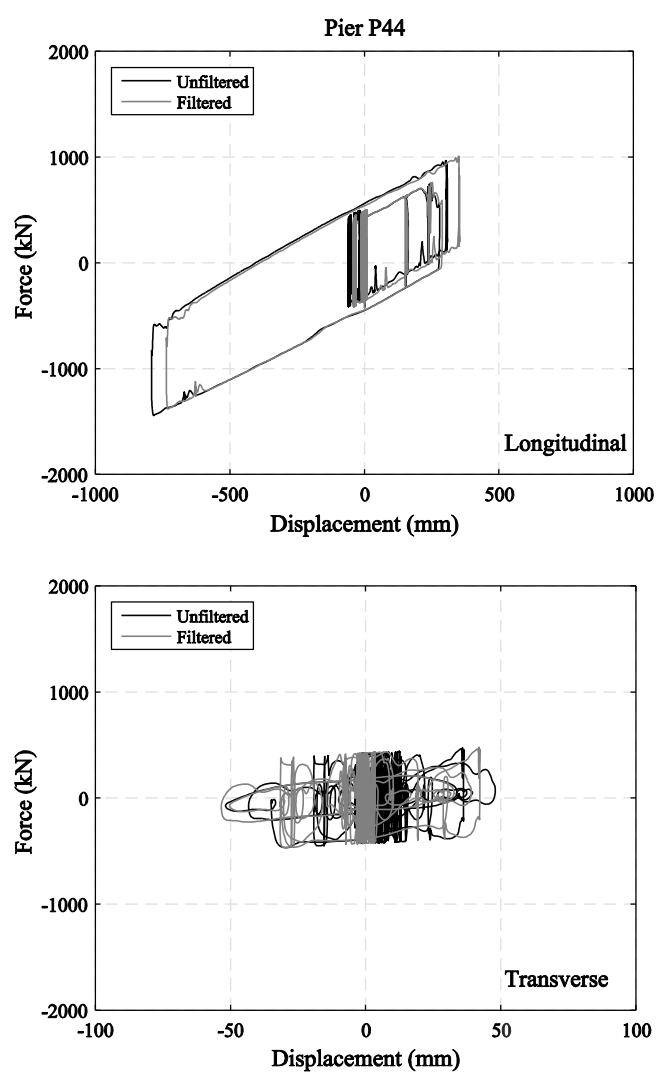

Fig. 8. Force-displacement hysteresis loops of the isolation system at pier P44 for "Case A" (ignoring fault crossing) using the unfiltered and filtered LUC record.

Fig. 9 summarizes the computed demands of deck displacement, pier top displacement, isolation displacement, isolation permanent displacement and pier drift for the analyzed bridge segment of "Case A" (Fig. 6a) obtained using the unfiltered and filtered LUC record. It can be observed that the differences in the demands of isolation displacement and pier drift computed using the unfiltered and filtered versions of the LUC record are $\sim 7 \%$ and $\sim 3 \%$, respectively. Finally, the computed demands of isolation permanent displacement for both cases are negligible and certainly not affected by the permanent ground displacement. These results suggest that standard processing schemes for ground motion records, which do not preserve the permanent ground displacement, may result in dynamic loads on structures in the vicinity of the surface fault rupture that are similar to those introduced by unfiltered ground motions.
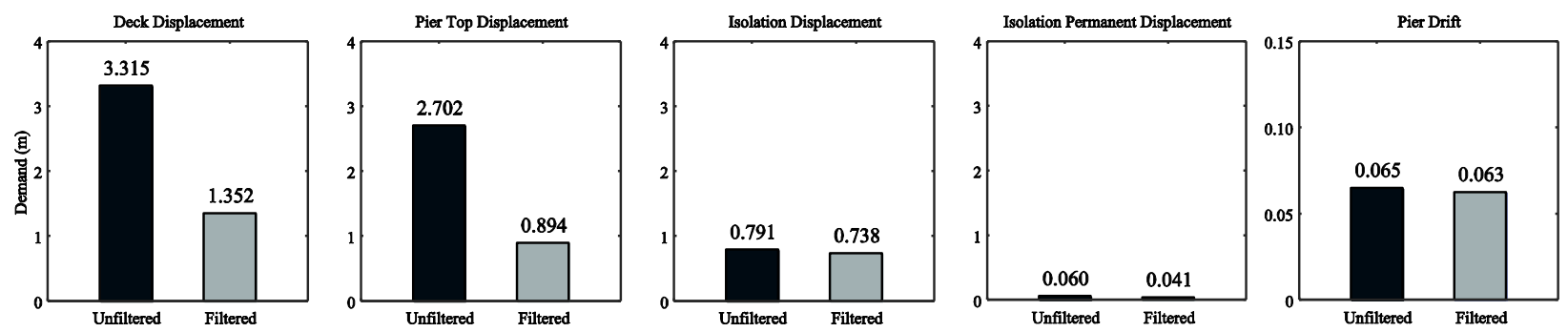

Fig. 9. Demands of deck displacement, pier top displacement, isolation displacement, isolation permanent displacement, and pier drift for "Case A" (ignoring fault crossing) using the unfiltered and filtered LUC record. 
Fig. 10 shows the time histories of deck displacement, pier top displacement, pier base displacement, isolation displacement and pier drift in the longitudinal and transverse directions for "Case B" at piers P44 and P45 obtained using the unfiltered and filtered LUC record. The force-displacement hysteresis loops of the isolation system at piers P44 and P45 are also presented in Fig. 11. It should be noted that piers P44 and P45 are located on opposite sides of the surface rupture (see Fig. 6b). Fig. 10 indicates that high-pass filtering greatly affects the time histories of pier top displacement, pier base displacement, isolation displacement, and pier drift. As a matter of fact, the offset between the isolation displacement time histories for the unfiltered and filtered versions of the LUC record is approximately equal to the permanent ground displacement. On the other hand, the deck displacements for piers P44 and P45 appear to be relatively small and the effect of high-pass filtering on their time histories is insignificant (Fig. 10). However, deck displacements for piers located away from the fault crossing location are significantly greater than those of piers P44 and P45, and high-pass filtering appears to have a significant effect on their time histories (i.e. similar to the effect observed in Fig. 10).
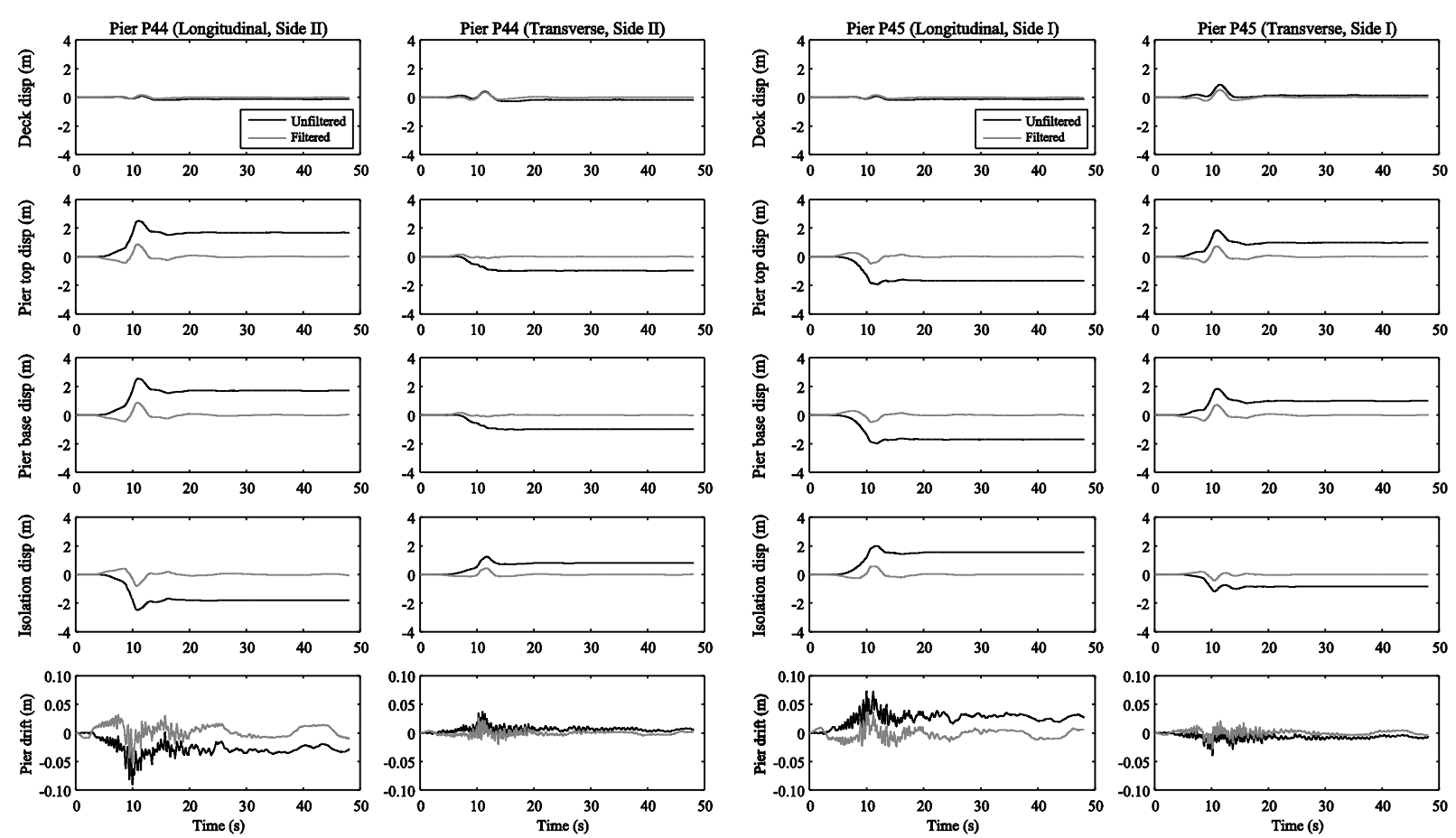

Fig. 10. Time history responses of deck displacement, pier top displacement, pier base displacement, isolation displacement, and pier drift at piers P44 and P45 for "Case B" (accounting for fault crossing) using the unfiltered and filtered LUC record. 

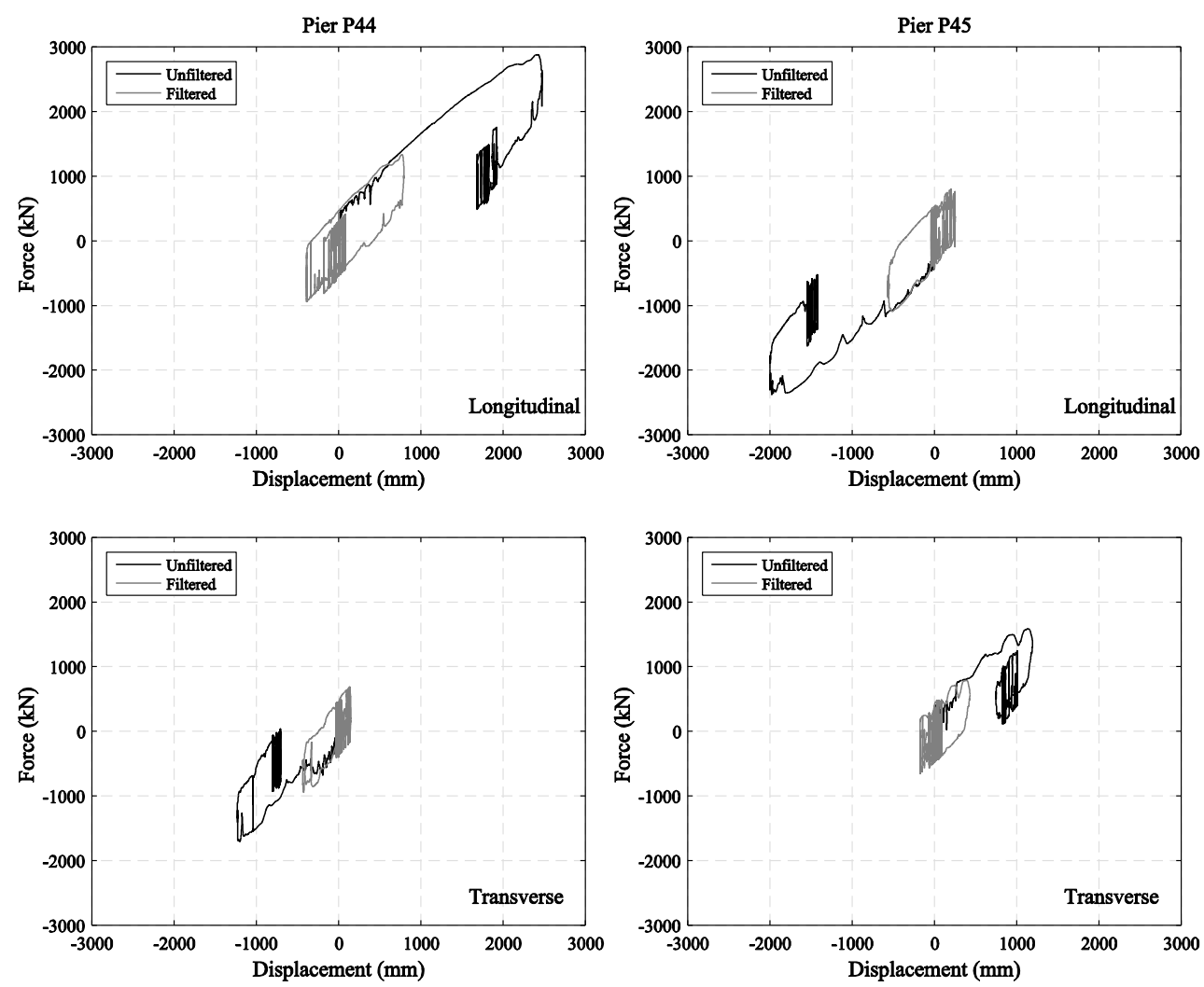

Fig. 11. Force-displacement hysteresis loops of the isolation system at piers P44 and P45 for "Case B" (accounting for fault crossing) using the unfiltered and filtered LUC record.

Fig. 12 summarizes the computed demands of deck displacement, pier top displacement, isolation displacement, isolation permanent displacement and pier drift for the analyzed bridge segment of "Case B" (Fig. 6b) obtained using the unfiltered and filtered LUC record. The isolation displacement demand computed using the unfiltered motion is about three times as much the demand computed using the filtered motion. Similarly, the pier drift demand computed with the unfiltered motion is $78 \%$ greater than the one computed with the filtered motion. Finally, the isolation permanent displacement demand computed using the unfiltered motion is $1.98 \mathrm{~m}$, whereas the one computed using the filtered motion is negligible.
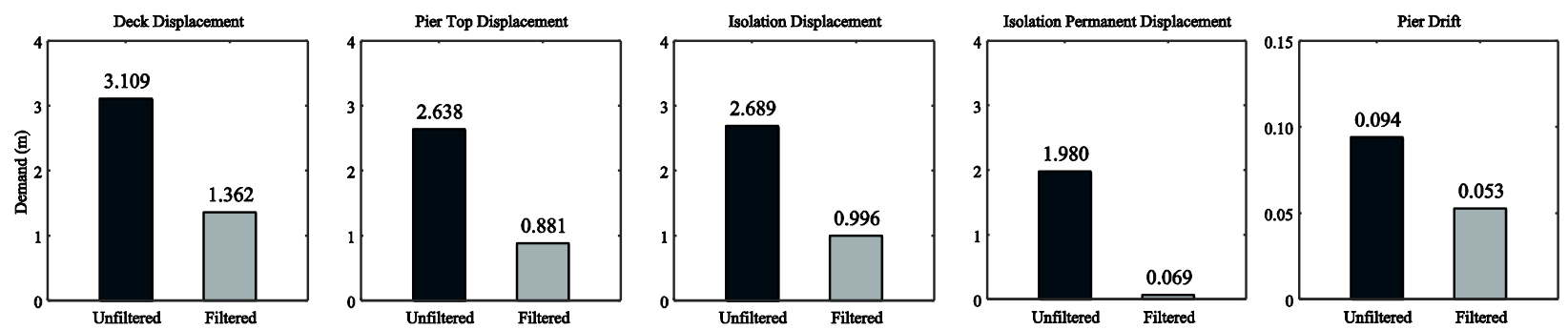

Fig. 12. Demands of deck displacement, pier top displacement, isolation displacement, isolation permanent displacement and pier drift for "Case B" (accounting for fault crossing) using the unfiltered and filtered LUC record. 


\section{Conclusions}

The effect of high-pass filtering on near-fault ground motion records is not only to remove the low-frequency noise, but also to eliminate the permanent ground displacement and reduce the dynamic ground displacement. This may considerably influence the calculated seismic response of a spatially extended engineering structure crossing a fault rupture zone. To demonstrate the importance of incorporating permanent ground displacements in the analysis and design of extended structures under specific fault crossing conditions, the dynamic response of a seismically isolated bridge located in the vicinity of a surface fault rupture ("Case A") or crossing a fault rupture zone ("Case B") was calculated by utilizing a near-fault ground motion record processed with and without a displacement offset.

For the seismically isolated bridge located in the vicinity of the surface fault rupture ("Case A"), the utilization of the high-pass filtered ground motion led to underestimating the demands of pier top, pier bottom and deck displacements. However, the demands of isolation displacement, isolation permanent displacement and pier drift were almost identical for both the unfiltered and filtered versions of the ground motion record. On the other hand, for the seismically isolated bridge traversed by a fault rupture zone ("Case B"), all response quantities were significantly underestimated when the high-pass filtered ground motion was used.

These results, though limited to a single bridge structure and a single ground motion input associated with the surface rupture of a vertical strike-slip fault, clearly indicate the importance of permanent ground displacement on the dynamic response of spatially extended engineering structures crossing fault rupture zones. These findings also suggest that caution should be utilized when high-pass filtered records obtained from strong motion databases are used for the analysis and design of extended structures potentially crossing fault rupture zones.

\section{Acknowledgements}

George P. Mavroeidis and Shuo Yang would like to acknowledge partial financial support provided by the U.S. National Science Foundation under Grant No. CMMI-1360734.

\section{References}

[1] Boore, D. M., and J. J. Bommer (2005). Processing of strong ground motion accelerograms: Needs, options and consequences, Soil Dynamics and Earthquake Engineering 25, 93-115.

[2] Douglas, J., and D. M. Boore (2011). High-frequency filtering of strong-motion records, Bulletin of Earthquake Engineering 9, 395-409.

[3] Wong, H. L., and M. D. Trifunac (1977). Effects of cross-axis sensitivity and misalignment on the response of mechanical-optical accelerographs, Bulletin of the Seismological Society of America 67, 929-956. 
[4] Todorovska, M. I. (1998). Cross-axis sensitivity of accelerographs with pendulum like transducersmathematical model and the inverse problem, Earthquake Engineering and Structural Dynamics 27, 10311051.

[5] Iwan, W. D., M. A. Moser, and C.-Y. Peng (1985). Some observations on strong-motion earthquake measurement using a digital accelerograph, Bulletin of the Seismological Society of America 75, 1225-1246.

[6] Chiu, H.-C. (1997). Stable baseline correction of digital strong-motion data, Bulletin of the Seismological Society of America 87, 932-944.

[7] Boore, D. M. (2003). Analog-to-digital conversion as a source of drifts in displacements derived from digital recordings of ground acceleration, Bulletin of the Seismological Society of America 93, 2017-2024.

[8] Bradner, H., and M. Reichle (1973). Some methods for determining acceleration and tilt by use of pendulums and accelerometers, Bulletin of the Seismological Society of America 63, 1-7.

[9] Graizer, V. M. (1989). On inertial seismometry, Physics of the Solid Earth - Izvestiya 25, 26-29.

[10] Graizer, V. M. (2005). Effect of tilt on strong motion data processing, Soil Dynamics and Earthquake Engineering 25, 197-204.

[11] Boore, D. M. (2001). Effect of baseline corrections on displacements and response spectra for several recordings of the 1999 Chi-Chi, Taiwan, earthquake, Bulletin of the Seismological Society of America 91, 1199-1211.

[12] Trifunac, M. D., and M. I. Todorovska (2001). A note on the useable dynamic range of accelerographs recording translation, Soil Dynamics and Earthquake Engineering 21, 275-286.

[13] Dreger, D., G. Hurtado, A. Chopra, and S. Larsen (2011). Near-field across-fault seismic ground motions, Bulletin of the Seismological Society of America 101, 202-221.

[14] Bolt, B. A., and N. A. Abrahamson (2003). Estimation of strong seismic ground motions, in International Handbook of Earthquake and Engineering Seismology, W. H. K. Lee, H. Kanamori, P. C. Jennings, and C. Kisslinger (eds), Part B, 983-1001, Academic Press, San Diego, CA.

[15] Mavroeidis, G. P., and A. S. Papageorgiou (2003). A mathematical representation of near-fault ground motions, Bulletin of the Seismological Society of America 93, 1099-1131.

[16] Alavi, B., and H. Krawinkler (2004). Behavior of moment-resisting frame structures subjected to near-fault ground motions, Earthquake Engineering and Structural Dynamics 33, 687-706.

[17] Mavroeidis, G. P., G. Dong, and A. S. Papageorgiou (2004). Near-fault ground motions, and the response of elastic and inelastic single-degree-of-freedom (SDOF) systems, Earthquake Engineering and Structural Dynamics 33, 1023-1049.

[18] Kalkan, E., and S. K. Kunnath (2006). Effects of fling-step and forward directivity on seismic response of buildings, Earthquake Spectra 22, 367-390.

[19] Bogdanov, V. I., and V. M. Graizer (1976). Determination of residual displacement of the ground from a seismogram, Reports of the USSR Academy of Sciences 229, 59-62 (in Russian).

[20] Graizer, V. M. (1979). Determination of the true ground displacement by using strong motion records, Physics of the Solid Earth - Izvestiya 15, 875-885. 
[21] Iwan, W. D., and X. Chen (1994). Important near-field ground motion data from the Landers earthquake, in Proceedings of the Tenth European Conference on Earthquake Engineering, Vienna, Austria.

[22] Boore, D. M., C. D. Stephens, and W. B. Joyner (2002). Comments on baseline correction of digital strongmotion data: Examples from the 1999 Hector Mine, California, earthquake, Bulletin of the Seismological Society of America 92, 1543-1560.

[23] Wu, Y.-M., and C.-F. Wu (2007). Approximate recovery of coseismic deformation from Taiwan strong-motion records, Journal of Seismology 11, 159-170.

[24] Emore, G. L., J. S. Haase, K. Choi, K. M. Larson, and A. Yamagiwa (2007). Recovering seismic displacements through combined use of $1-\mathrm{Hz}$ GPS and strong-motion accelerometers, Bulletin of the Seismological Society of America 97, 357-378.

[25] Akkar, S., and D. M. Boore (2009). On baseline corrections and uncertainty in response spectra for baseline variations commonly encountered in digital accelerograph records, Bulletin of the Seismological Society of America 99, 1671-1690.

[26] Chao, W.-A., Y.-M. Wu, and L. Zhao (2010). An automatic scheme for baseline correction of strong-motion records in coseismic deformation determination, Journal of Seismology 14, 495-504.

[27] Bock, Y., D. Melgar, and B. W. Crowell (2011). Real-time strong-motion broadband displacements from collocated GPS and accelerometers, Bulletin of the Seismological Society of America 101, 2904-2925.

[28] Wang, R., B. Schurr, C. Milkereit, Z. Shao, and M. Jin (2011). An improved automatic scheme for empirical baseline correction of digital strong-motion records, Bulletin of the Seismological Society of America 101, 2029-2044.

[29] Chanerley, A. A., N. A. Alexander, J. Berrill, H. Avery, B. Halldorsson, and R. Sigbjornsson (2013). Concerning baseline errors in the form of acceleration transients when recovering displacements from strong motion records using the undecimated wavelet transform, Bulletin of the Seismological Society of America 103, 283-295.

[30] Melgar, D., Y. Bock, D. Sanchez, and B. W. Crowell (2013). On robust and reliable automated baseline corrections for strong motion seismology, Journal of Geophysical Research: Solid Earth 118, 1177-1187.

[31] Graizer, V. M. (2010). Strong motion recordings and residual displacements: What are we actually recording in strong motion seismology? Seismological Research Letter 81, 635-639.

[32] Trifunac, M. D. (1971). Zero baseline correction of strong-motion accelerograms, Bulletin of the Seismological Society of America 61, 1201-1211.

[33] Trifunac, M. D., and V. W. Lee (1974). A note on the accuracy of computed ground displacements from strong-motion accelerograms, Bulletin of the Seismological Society of America 64, 1209-1219.

[34] Wald, D. J., and T. H. Heaton (1994). Spatial and temporal distribution of slip for the 1992 Landers, California, earthquake, Bulletin of the Seismological Society of America 84, 668-691.

[35] Chen, X. (1995). Near-field ground motion from the Landers earthquake, Ph.D. Dissertation, California Institute of Technology, Pasadena, California. 
[36] Ancheta, T. D., R. B. Darragh, J. P. Stewart, E. Seyhan, W. J. Silva, B. S.-J. Chiou, K. E. Wooddell, R. W. Graves, A. R. Kottke, D. M. Boore, T. Kishida, and J. L. Donahue (2013). PEER NGA-West2 Database, Report No. PEER-2013/03, Pacific Earthquake Engineering Research Center, Berkeley, CA

[37] Kamai, R., and N. Abrahamson (2015). Are near-fault fling effects captured in the new NGA West2 ground motion models? Earthquake Spectra 31, 1629-1645.

[38] Seismosoft (2013). SeismoSignal v5.1 - A computer program for signal processing of strong-motion data, available from http://www.seismosoft.com

[39] Ucak, A., G. P. Mavroeidis and P. Tsopelas (2014). Behavior of a seismically isolated bridge crossing a fault rupture zone, Soil Dynamics and Earthquake Engineering 57, 164-178.

[40] ABAQUS Inc. (2013). ABAQUS analysis user's manual, ABAQUS Inc, Providence, RI.

[41] Burks, L. S., and J. W. Baker (2014). Fling in near-fault ground motions and its effect on structural collapse capacity, in Proceedings of the Tenth U.S. National Conference on Earthquake Engineering, Anchorage, AK. 